\title{
DESAIN MEDIA KOMUNIKASI VISUAL PENUNJANG EVENT WISUDA
}

\author{
Triyono $^{1}$ \\ Kemal Salahuddin ${ }^{2}$ \\ Hendi Setiawan ${ }^{3}$ \\ Jurusan Teknik Informatika STMIK Raharja ${ }^{1}$, Jurusan Manajemen informatika AMIK Raharja \\ Informatika ${ }^{2}$, Jurusan Sistem Informasi STMIK Raharja ${ }^{3}$ \\ Email: triyono@raharja.info, hendi.setiawan@raharja.info
}

Diterima: 7 Desember 2016/ Disetujui : 21 Desember 2016

\begin{abstract}
Graduation organizing events in an educational institution is the most awaited moment by the student who has completed the learning. That Moment is the awarding accordance to each education level. STMIK Raharja is a computer-based educational institution in Tangerang city which organizes Graduation event for Diploma and Bachelor's Degree annually. The implementation of the graduation is the biggest event to the colleges therefore the preparation is organized carefully starting from the committee formation. Refer to this event so that required a new media visual communication to support the implementation runs attractive and successful. This event is held not only to reward graduates but also to promote the college to invited guests or public. The aims of this study is to determine the media used to be effective in organizing events and drafting Graduation visual communication media to support the event as an image of the college. The methodology used is objective visual, strategy visual, copy writing, art directing and rough layout designing, comprehensive layout, and final artwork. The media visual communication are designed to 9 items such as banners outside and inside, banners up and down, Backdrop, Invitation Cards and contents of the invitation, book Cover, media advertised of Greetings \& Success addressed to Graduations in mass media and souvenir such as fans and glasses.
\end{abstract}

Keywords: Graduation, event, Media Visual Communication, Design

\begin{abstract}
ABSTRAK
Penyelenggaraan event Wisuda di suatu Institusi Pendidikan adalah moment yang sangat dinantikan oleh setiap peserta pendidikan yang telah selesai masa studinya. Moment tersebut merupakan penobatan gelar sesuai dengan jenjang pendidikan masing-masing. Perguruan Tinggi Raharja adalah salah satu lembaga pendidikan yang berbasis komputer di Kota Tangerang yang setiap tahunnya menyelenggarakan event Wisuda Gelar Ahli Madya untuk jenjang pendidikan Diploma dan Gelar Sarjana untuk jenjang pendidikan S1. Di Perguruan Tinggi Raharja Penyelenggaraan Wisuda setiap tahunnya merupakan event besar, oleh karena itu mulai dari pembentukan panitia, persiapan acara sampai pelaksanaan membutuhkan persiapan yang matang. Mengacu pada penyelenggaraan event Wisuda Perguruan Tinggi Raharja tahun sebelumnya bahwa dalam setiap penyelenggaraan selalu membutuhkan sarana media komunikasi visual dengan desain yang baru dan menarik sebagai penunjang suksesnya event tersebut. Penyelenggaraan event besar tersebut selain merupakan penobatan terhadap kelulusan juga sekaligus dijadikan momen promosi tentang Perguruan Tinggi Raharja melalui tamu undangan, peserta Wisuda dan masyarakat pada umumnya. Penelitian ini bertujuan untuk mengetahui media yang digunakan agar efektif dalam mensukseskan penyelenggaraan event Wisuda dan membuat rancangan media komunikasi visual sebagai penunjang event wisuda yang sesuai dengan citra dari perguruan tinggi Raharja. Metodologi yang digunakan adalah visual obyective, visual strategy, copy writing, art directing dan designing-layout kasar, layout komprehensif, dan final artwork. Desain media komunikasi visual yang akan dibuat berjumlah 9 item diantaranya Spanduk luar dan dalam, Umbul-umbul atas dan bawah, Backdroup, Kartu
\end{abstract}


Undangan dan isi undangan, Cover Buku Wisuda, media iklan Ucapan Selamat \& Sukses yang ditujukan kepada peserta Wisuda yang dipasang di mass media, kipas dan gelas.

Kata Kunci: Desain, Media Komunikasi Visual, Wisuda, Event

\section{PENDAHULUAN}

Penyelenggaraan event Wisuda di suatu Pendidikan adalah moment yang sangat dinantikan oleh setiap peserta pendidikan yang telah selesai masa studinya. Moment tersebut merupakan penobatan gelar sesuai dengan jenjang pendidikan masing-masing.

Perguruan Tinggi Raharja, adalah salah satu lembaga pendidikan tinggi berbasis komputer yang berada di kota Tangerang. Perguruan Tinggi Raharja setiap tahunnya menyelenggarakan event Wisuda, yang meluluskan mahasiswa/i untuk mendapatkan gelar Ahli Madya (A.Md.), untuk jenjang pendidikan diploma dan gelar sarjana untuk jenjang pendidikan Strata 1 (S1). Di Perguruan Tinggi Raharja Penyelenggaraan Wisuda setiap tahunnya merupakan event besar, oleh karena itu mulai dari pembentukan panitia, persiapan acara sampai pelaksanaan membutuhkan persiapan-persiapan yang matang.

Mengacu pada penyelenggaraan Wisuda di tahun sebelumnya yang hanya memberikan media komunikasi melalui spanduk, umbul-umbul, undangan dan backdroup, maka kali ini menambahkan media komunikasi tersebut dengan souvenir yang berupa kipas dan gelas. penyelenggaraan event Wisuda Perguruan Tinggi Raharja selalu membutuhkan sarana media komunikasi visual dengan perancangan desain yang baru dan menarik sebagai penunjang suksesnya event tersebut. Adapun desain ini dibuat sebagai penunjang sarana informasi dan promosi yang selalu update yang akan disampaikan oleh pihak Perguruan Tinggi kepada calon wisudawan/wati, orang tua/wali, pengusaha, lembaga pemerintahan terkait dan pihak-pihak terkait lainnya. Event besar tersebut selain penobatan untuk kelulusan juga sekaligus dapat dijadikan momentum promosi tentang Perguruan Tinggi Raharja melalui tamu undangan dan perserta Wisuda.

\section{RUMUSAN MASALAH}

Saat ini bukan hanya perkembangan teknologi saja yang sangat cepat, melainkan juga perkembangan akan media informasi yang dimana hampir di segala bidang membutuhkan media tersebut (dalam media cetak atau elektronik) yang digunakan sebagai alat bantu komunikasi untuk menyampaikan suatu pesan yang bersifat Public Relations (hubungan masyarakat) yaitu untuk mempengaruhi atau membujuk dan memberikan kesan kepada audience terhadap apa yang diinformasikan oleh sebuah badan usaha. Salah satu dari media informasi tersebut adalah dalam bentuk Event wisuda 2010/2011 yang berfungsi sebagai media pendukung promosi untuk memperkenalkan dan memberikan pemahaman tentang Perguruan Tinggi Raharja sebuah badan usaha kepada masyarakat luas agar menjadi tahu dan yakin akan informasi tersebut. Perancangan media informasi dan promosi dalam bentuk media event adalah bagian dari media komunikasi visual dengan perancangan desain yang baru dan menarik sebagai penunjang suksesnya event dan mengarahkan seseorang agar dapat mengenal Perguruan Tinggi Raharja, lalu memahaminya dan berubah sikap, menyukai, yakin, kemudian akhirnya menjadi calon mahasiswa Perguruan Tinggi Raharja. Untuk memenuhi kebutuhan dalam penyampaian informasi menjadi lebih komunikatif dan efektif dan mencerminkan citra perguruan tinggi Raharja dalam event wisuda 2010/2011 maka perlu dibuatlah perancangan media komunikasi visual yang efektif dan mencerminkan citra perguruan tinggi Raharja sebagai penunjang event wisuda

\section{METODE PENELITIAN}

Metode penelitian yang digunakan dalam penelitian ini adalah metode observasi, metode wawancara, dan metode studi pustaka.

\section{Metode Observasi}

Metode pengumpulkan data untuk mendapatkan hal-hal yang dibutuhkan dalam penyusunan penelitian dengan cara mendatangi tempat penelitian secara langsung.

2. Wawancara 
Dalam hal ini dilakukan melakukan tanya jawab secara langsung kepada pihak yang terkait untuk mengetahui hal yang sedang diteliti guna memperoleh informasi yang dibutuhkan.

3. Studi Pustaka

Untuk mendapatkan materi yang digunakan sebagai landasan teoritis dalam penelitian, penulis mencari berbagai sumber yaitu dengan cara membaca buku-buku atau literatur yang berisi tentang teori-teori yang berkaitan dengan permasalahan yang di bahas.

\section{TINJAUAN PUSTAKA}

\section{Pengertian Media}

Berikut adalah beberapa pengertian media :

1. Media adalah sarana untuk menyampaikan pesan atau informasi kepada publik dengan menggunakan berbagai unsur komunikasi grafis seperti teks, gambar atau foto.[1]

2. Media adalah segala bentuk yang digunakan untuk menyalurkan informasi. Pengertian media yang diberikan AECT (Association for education communication and tecnology) ini menunjukkan bahwa istilah "media" memiliki makna yang sangat umum.[2]

3. Media adalah bentuk jamak dari medium-medium komunikasi diartikan sebagai alat perantara yang sengaja dipilih komunikator untuk menghantarkan pesannya agar sampai ke komunikan. Jadi, unsur utama dari media komunikasi adalah pemilihan dan penggunaan alat perantara yang dilakukan komunikator dengan sengaja. Artinya, hal ini mengacu kepada pemilihan dan penggunaan teknologi media komunikasi.[3]

Dapat disimpulkan bahwa media adalah segala bentuk dalam berbagai unsur komunikasi grafis untuk menyampaikan informasi kepada public

\section{Alternatif Media}

Macam-macam media komunikasi grafis dapat di kelompokkan sebagai berikut :

a. Media Komunikasi cetak atau visual, contohnya poster (dalam dan luar), stiker, sampul buku, pembungkus, selipat (folder), selebaran (leaflet), amplop dan kop surat, tas belanja, katalog,iklan majalah dan surat kabar.

b. Media Luar Ruangan, contohnya seperti spanduk (banner), papan nama, umbul-umbul, neon box, neon sign, billboard, baliho, mobil books.

c. Media Elektronik, contohnya radio, televisi, internet, film, program video, animasi komputer.

d. Tempat Pajang (Display), contohnya etalase (window display), point of purchase, desain gantung, floor stand.

e. Barang Kenangan, contohnya kaos, topi, payung, gelas, aneka souvenir, tas, dan sebagainya.[4]

\section{Definisi Desain}

Desain merupakan art direction, yaitu penampilan visual secara menyeluruh dari iklan. Hasil kerjasama art direction dan copy writer ( berupa konsep verbal dan visual ) dipadukan secara sinergis kedalam desain melalui proses standar, yaitu membuat sketsa-sketsa kasar, menentukan alternative desain hingga final artwork.[5]

\section{Teori Desain komunikasi visual}

Desain komunikasi visual sering disebut dengan ilmu yang mempelajari tentang media untuk menyampaikan informasi, konsep, ide, gagasan melalui bentuk lambing dan symbol yang mudah dicerna atau ditangkap dengan indra penglihat dengan menggunakan bahasa visual. Desain komunikasi visual bisa juga disebut dengan Graphic Design keduanya adalah ilmu yang mempelajari tentang media penyampaian pesan, ide, ajakan kepada khalayak ramai, gagasan melalui bentuk, lambang dan simbol yang mudah dicerna atau ditangkap dengan indra penglihatan. Desain komunikasi visual dapat juga diartikan sebagai ilmu yang mempelajari konsep komunikasi dan ungkapan kreatif, tehnik dan media untuk meyampaikan pesan dan gagasan secara visual, termasuk audio dengan mengolah elemen desain grafis berupa bentuk dan gambar, huruf dan warna, serta tata letaknya, sehingga pesan dan gagasan dapat diterima oleh sasarannya, tetapi yang jelas desain grafis erat kaitannya dengan proses cetak. Melalui media ini desain grafis berfungsi sebagai jembatan 
penghubung antara pihak yang berkepentingan didalam dunia bisnis dan hal - hal yang berkaitan dengan media komunikasi.

Desain Komunikasi Visual adalah solusi komunikasi yang menjembatani antara pemberi informasi dengan publik, baik secara perorangan, kelompok, lembaga maupun masyarakat secara luas yang diwujudkan dalam bentuk komunikasi visual.

Keindahan desain komunikasi visual mengandung unsur - unsur estetika yang terdiri dari : garis, bentuk, warna, cahaya, ruang, tekstur, keseimbangan, keserasian, proporsi, skala, irama, disamping fungsi tehnik dan pesan yang terkandung.[6]

\section{Layout}

Layout arti katanya secara bahasa adalah Tata Letak. Menurut salah satu teorinya, layout adalah usaha untuk menyusun, menata atau memadukan unsur-unsur komunikasi grafis (teks, gambar, tabel dll) menjadi komunikasi visual yang komunikatif, estetik dan menarik.[7]

\section{Jenis Layout}

Jenis jenis layout diantaranya adalah:

a. Layout Kasar adalah Penerapan elemen-elemen desain media yang nantinya akan dipergunakan dalam perancangan media katalog yang disertai acuan standarisasi pada desain yang akan dibuat,umumnya dibuat dengan tampilan hitam putih, dibuat dengan coretan atau sketsa dengan menggunakan pensil gambar. Layout Kasar diperlukan sebagai panduan pada saat diproses desain dengan menggunakan aplikasi komputer.

b. Layout Komprehensif adalah Layout Komprehensif adalah Proses desain yang sudah memasuki tahap komputerisasi san pewarnaan, namun tahap ini belum selesai seluruhnya, karena masih harus mengalami proses revisi.

c. Final Artwork adalah hasil akhir dari layout komprehensif yang telah diperbaiki. Dimana tahap ini merupakan hasil akhir atau finishing yang kemudian dapat digunakan untuk acuan saat proses produksi.[8]

\section{Pengertian Promosi}

Promosi adalah tindakan menginformasikan atau meningkatkan konsumen tentang spesifikasi produk atau merek. Promosi mempunyai kekuatan untuk menyampaikan pesan, dan diperlukan perancangan khusus agar promosi tersebut memiliki visual yang kuat dan menciptakan keserasian didalam rangkaian pemasaran, karena promosi adalah berkaitan langsung dalam upaya untuk memperkenalkan produk kepada konsumen dengan memikat hati mereka melalui pemberian kesankesan baik, yang mampu diingat dan dirasakan oleh konsumen.[9]

\section{Pengertian Adobe Photoshop Cs5}

Adobe Photoshop adalah suatu perangkat lunak yang canggih yang dapat digunakan untuk membuat, menyunting dan memanipulasi tampilan termasuk mengoreksi warna dan memberi efek tampilan atas sebuah gambar atau photo, hasil dari program ini merupakan sebuah gambar atau image, didalam komputer grafis terbagi menjadi dua kelompok yaitu Gambar Bitmap dan Gambar Vektor.[8]

Dengan kemampuan pengolahan bitmap yang sangat baik, menjadikan Adobe Photoshop menjadi standar yang umum digunakan didalam pengolahan objek bitmap. Photoshop menyimpan beberapa kemampuan yang sangat baik untuk membuat gambar selayaknya menggunakan aplikasi berbasis vektor. Akan tetapi hal tersebut membutuhkan pemahaman konsep dasar pembentukan kurva vektor yang tidak dapat ditinggalkan oleh aplikasi dalam mengolah bitmap seperti photoshop. Konsep dasar yang harus dipahami adalah : manajemen layer, pembuatan path, dan seleksi. Toolbox berfungsi sebagai tombol pengganti perintah yang dipergunakan untuk mempercepat pekerjaan. Nama-nama toolbox terdiri atas Marquee tools, Lasso tools, Magic Wand tool, Move tool, Crop tool, Slice tool, Healing brush tool, Pencil tool, Clone Stamp tool, History Brush tool, Eraser tool, Paint Bucket tool, Blur tool, Path Component Selection tool, Type tool, Pen tool, Zoom tool, Eyedroper Hand tool, dan sebagainya.[10] 


\section{PEMBAHASAN}

\section{Perencanaan Media}

Perencanaan media yang di ajukan digunakan sebagai media penunjang informasi tentang penyelenggaraan event Wisuda pada Perguruan Tinggi Raharja. Adapun jenis media yang direncanakan untuk dirancang adalah media spanduk luar ruangan digunakan sebagai penujuk lokasi penyelenggaraan event dan ucapan selamat datang kepada para wisudawan, sedangkan spanduk dalam ruangan digunakan sebagai ucapan selamat kepada para wisudawan dan ucapan-ucapan motto tentang Perguruan Tinggi Raharja sebagai kampus IT dan sebagai kampus unggulan. Media umbulumbul digunakan sebagai penyemarak event dan petunjuk lokasi penyelenggaraan wisuda. Media undangan dipakai sebagai sarana untuk mengundang kepada para wali wisudawan. Media buku peserta Wisuda digunakan sebagai bukti keikutsertaan wisuda sekaligus sebagai kenang-kenangan kepada para wisudawan. Media backdroup digunakan sebagai latar belakang panggung sekaligus sebagai dekor panggung penyelenggaraan wisuda. Media iklan Ucapan Selamat \& Sukses yang dikoran digunakan sebagai pemberitahuan bagi mahasiswa yang sudah lulus

\section{Program Media}

Media-media yang dirancang direncanakan pemasangan dan pemakaiannya disesuaikan dengan kebutuhan sosialisasi ataupun penyelenggaraan event. Media spanduk luar ruangan akan dipasang satu atau dua hari sebelum pelaksanaan event. Media spanduk dalam ruangan dipersiapkan satu hari sebelum pelaksanaan. Backdroup dipasang mulai dua hari sebelum pelaksanaan karena satu hari sebelum pelaksanaan dilakukan gladi bersih. Media undangan digunakan kurang lebih dua minggu sebelum pelaksanaan harus sudah di sebar atau disampaikan kepada pihak-pihak yang dituju. Media umbul-umbul dipasang hari mendekati pelaksanaan event bisa dipasang di lingkungan kampus maupun lokasi penyelenggaraan event. Buku wisuda akan dibagikan bersamaan para wisudawan melakukan registrasi. Media iklan ucapan kepada seluruh peserta wisuda diterbitkan pas hari pelaksanaan event wisuda.

\section{Konsep Kreatif}

Konsep kreatif yang ingin dituangkan ke dalam media-media penunjang penyelengaraan event wisuda adalah sebuah ide kreatif yang lebih cenderung pengembangan ornamen, mengolah warna dan mengolah jenis huruf serta elemen grafis pendukung lainnya. rancangan yang akan ditampilkan lebih mengarah kesan teknologi. Hal ini membutuhkan pemikiran yang serius dan teliti agar dalam menuangkan ide kreatif atau gagasan dapat sesuai dengan tema yang telah ditentukan.

\section{Perencanaan Visual}

Lepas dari tema yang ditentukan dalam event wisuda tersebut Penulis ingin merancang sebuah pengembangan typografi yang diperuntukkan identitas event wisuda 2011, diolah dengan menggunakan jenis huruf Banff-Normal-Reguler, sehingga menjadi kata Wisuda 2011 yang mempunyai karakter khusus yang diarahkan identik dengan penyelenggaraan, selain dari itu akan dirancang bentuk ornament tertentu yang dapat dipergunakan sebagai materi ciri khas satu kesatuan dari media-media yang dirancang.

\section{Tujuan Visual}

Suasana yang ingin disampaikan oleh penulis melalui hasil rancangan media event tersebut yaitu, menciptakan suasana yang berkesan teknologi (hi-tech), elegan dan dinamis mulai dari tata letak (layout), warna dan tipografi disesuaikan dengan image atau citra Perguruan Tinggi Raharja.

\section{Strategi Visual}

Penyajian visualisasi pada perancangan media informasi yaitu dengan pembentukan objek-objek dan pengaturan tata letak dengan menggunakan Adobe Illustrator5 dan Adobe Photoshop5, software pendukung lainnya disesuaikan dengan kebutuhan rancangan. Adapun strategi visual yang ingin disampaikan adalah dengan pendekatan secara emosional yang terkesan formal namun tegas mulai dari segi warna, tata letak atau layout, jenis huruf dan gaya penampilan grafis serta dalam bentuk penyampaiannya dilakukan secara sederhana agar audience lebih dapat memahami, dari pencitraan 
tersebut diharapkan dapat merubah sikap masyarakat, setelah mengetahui kelebihan-kelebihan melalui bentuk-bentuk media yang digunakan.

\section{Penulisan Naskah (Copy Writing)}

Rancangan media penunjang event wisuda terdapat unsur-unsur komunikasi grafis seperti teks (tulisan), ilustrasi (foto atau image) dan warna. Salah satunya adalah teks (tulisan) yang mempunyai kharakter khusus diperlukan dalam perancangan agar penyampaian misi media mudah dimengerti dan tepat sasaran, teks akan menyesuaikan bentuk-bentuk media yang telah direncanakan terdiri dari beberapa bagian yaitu judul (headline), subjudul, naskah (body copy), logo (logotype).

Berikut adalah penjelasan dari masing-masing bagian dari teks (tulisan).

1. Judul (headline)

Bagian terpenting dari teks yang menarik perhatian dan merupakan hal yang pertama kali dibaca. Judul akan mengarahkan pembaca untuk lebih jauh mengetahui tentang isi dari sebuah pesan atau informasi yang ada di dalamnya.

2. Subjudul

Lanjutan keterangan dari judul yang akan menjelaskan makna atau arti dari judul, pada umumnya subjudul akan lebih panjang dari judul. Subjudul dapat juga disebut sebagai kalimat peralihan yang mengarahkan pembaca dari judul ke kalimat pembuka naskah (body copy).

1. Naskah (body copy)

Kalimat yang menerangkan lebih rinci tentang isi pesan yang ingin disampaikan, berfungsi untuk mengarahkan pembaca dalam mengambil sikap berpikir dan bertindak lanjut. Secara kreatif bentuk naskah atau body copy dapat dikombinasikan dengan gambar dalam berbagai bentuk.

2. Logo

Tanda pengenal atau identitas yang tetap dari perusahaan, institusi, atau sebuah lembaga. Biasanya dibuat secara singkat, sederhana dan komunikatif dengan menggunakan huruf dan gambar agar lebih mudah diingat.

\section{Pengarahan Visualisasi (Art Directing)}

Agar desain media-media komunikasi visual yang dirancang terlihat menarik dan memiliki karakter tersendiri, maka dalam proses visualisasi harus memperhatikan hal-hal yang akan mempengaruhi kegunaan dan nilai artistic sebuah media. Dalam menentukan unsur-unsur warna yang dipilih, jenis huruf yang dipakai, tata letak atau layout yang diterapkan, gaya penampilan grafis yang sesuai serta model yang dipilih untuk ditampilkan di setiap rancangan media. Oleh sebab itu, dalam menjabarkan visualisasi yang dipilih dan dapat dipergunakan pada media-media rancangan :

1. Tonalitas warna yang dipergunakan adalah warna putih, orange, kuning, dan hijau, karena warna kuning menciptakan keoptimisan dan pengharapan serta warna hijau menciptakan suasana alam, pembaharuan dan sesuai dengan citra atau image dari Perguruan Tinggi Raharja atau biasa disebut dengan Green Campus.

2. Jenis huruf yang dipergunakan adalah jenis huruf Bookman Old Style, Arial dan ESCHfont Regular karena jenis huruf tersebut berkesan teknologi, formal dan mudah dibaca oleh setiap audience.

3. Tata letak atau layout yang dipergunakan adalah dengan menata atau menyatukan unsur-unsur komunikasi visual mulai dari teks, gambar dan warna agar menjadi media komunikasi visual yang komunikatif dan dapat menarik perhatian kepada seluruh audience.

4. Gaya penampilan grafis yang dipergunakan adalah menciptakan kesan teknologi (hi-tech), elegan dan dinamis, karena Perguruan Tinggi Raharja merupakan salah satu institusi pendidikan dalam bidang informasi dan komputer.

5. Model yang dipergunakan dalam buku dan web profil adalah gambar dan foto aset-aset atau kegiatan yang ada di Perguruan Tinggi Raharja, karena untuk mewakili dari keterangan teks yang ada dalam buku dan web profil agar konsumen (calon mahasiswa baru, relasi dan masyarakat) lebih mudah mengerti dan memahami dari isi informasi tersebut.

\section{Layout Kasar (Rough Layout)}


Sebelum membuat rancangan melalui komputer, penulis terlebih dahulu membuat layout kasar dengan menggunakan alat gambar pensil dan kertas, untuk memberikan kebebasan penulis dalam menuangkan ide gagasan yang sesuai dengan perancangan, selain itu sebagai pedoman pada saat proses desain dengan menggunakan komputer. Proses-proses berikutnya, dalam hal ini yang dimaksud layout kasar adalah penempatan elemen-elemen desain yang nantinya akan dipergunakan dalam perancangan media komunikasi yang disertai acuan standarisasi pada desain yang akan dibuat, umumnya dibuat hitam putih, salah satu diantaranya dapat dibuat dengan coretan atau sketsa dengan menggunakan pensil gambar.

Pada tahap ini penulis akan menyesuaikan terhadap banyaknya jenis media yang akan dirancang dari media pertama hingga selanjutnya.

\section{Layout kasar Media Spanduk Luar Ruangan}

Desain spanduk luar ruangan menampilkan logo Perguruan Tinggi Raharja, logo ISO Kalimat ucapan Selamat Datang yang ditujukan kepada para wisudawan, diolah dan dilengkapi dengan unsur-unsur grafis lainnya. Berikut adalah layout kasar yang dibuat secara manual dengan menggunakan goresan pensil gambar.

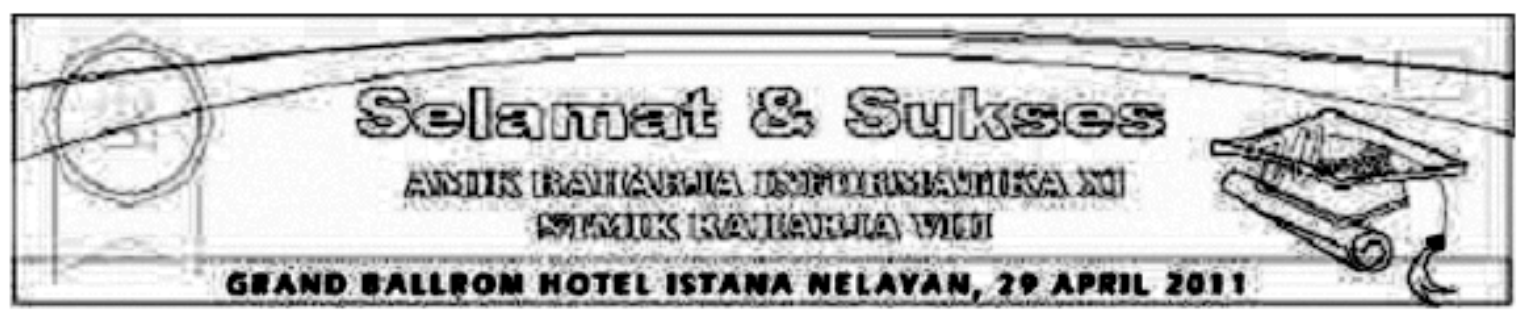

\section{Gambar 1}

Layout Kasar Desain Media spanduk luar ruangan

\section{Layout Kasar Desain Media Spanduk Dalam Ruangan}

Pada media spanduk dalam ruangan ini akan ditampilkan mengenai ucapan selamat \& Sukses kepada para tamu undangan dan wisudawan.

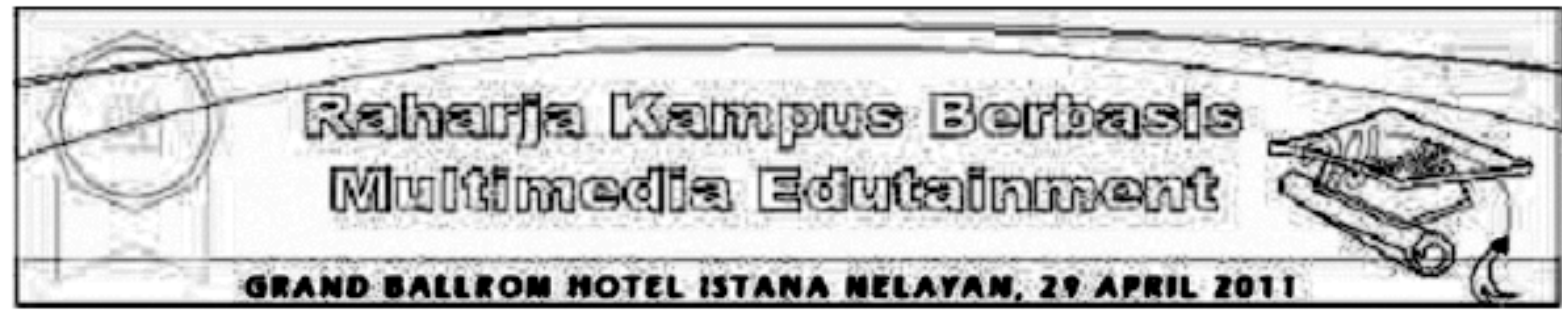

\section{Gambar 2}

Layout kasar Desain Media Spanduk Dalam Ruangan

\section{Layout Kasar Media Umbul-umbul Bawah}

Pada desain media umbul-umbul Bawah berisi logo atau identitas institusi, logo ISO, kata wisuda 2011, tanggal, bulan dan tahun penyelenggaraan, selain itu juga didukung ornamen desain lain dalam membangun nilai-nilai artistik rancangan desain. 


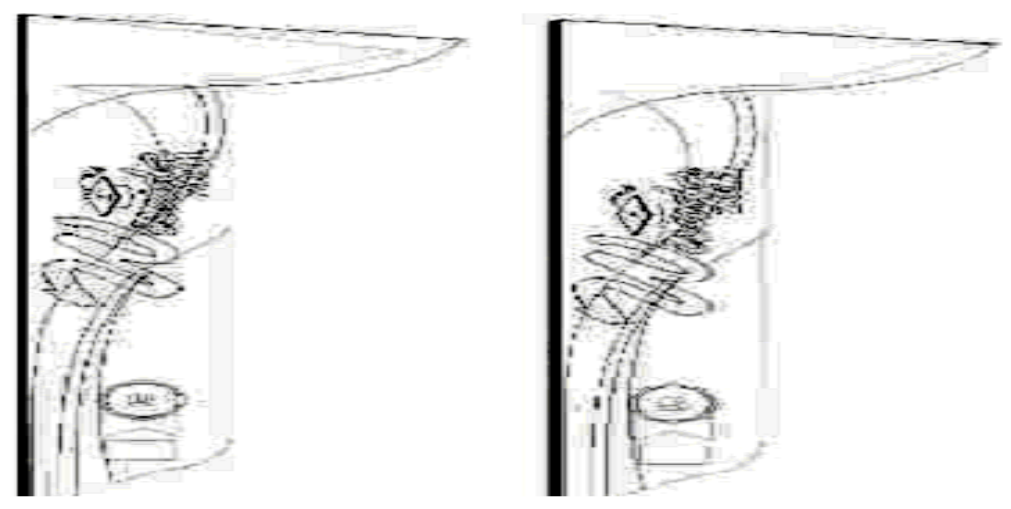

Gambar 3

Layout Kasar Media Umbul-umbul Bawah

\section{Layout Kasar Desain Umbul-umbul Atas}

Desain Umbul-umbul Atas berisi logo, identitas instituís, logo ISO, kata wisuda 2011 dan gambar boneka komputer memakai toga, selain itu juga didukung ornamen desain lain dalam membangun nilai-nilai artistik rancangan desain.

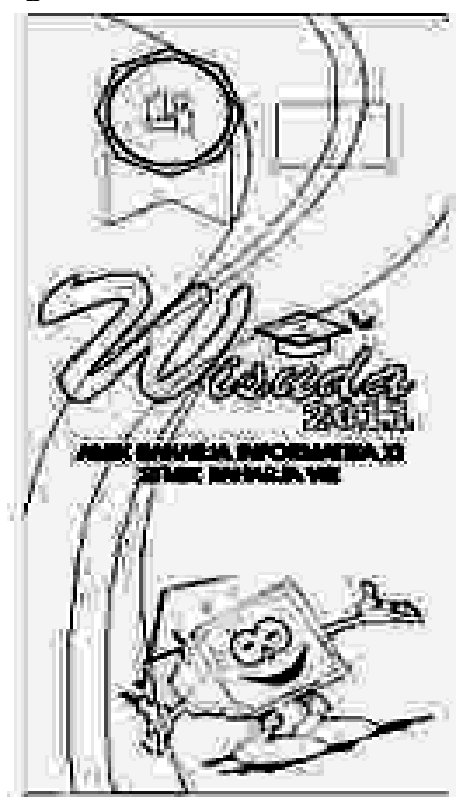

\section{Gambar 4}

Layout Kasar Media Umbul-umbul Atas

\section{Layout Kasar Desain Backdroup}

Desain backdroup berisi dua logo instituís, logo ISO dan kata WISUDA XI AMIK RAHARJA INFORMATIKA DAN WISUDA VIII STMIK RAHARJA, Get The Better Computer Science dan tempat penyelenggaraan event wisuda, didukung dengan ornamen grafis lainnya guna membangun nilai-nilai rancangan desain backdroup. 


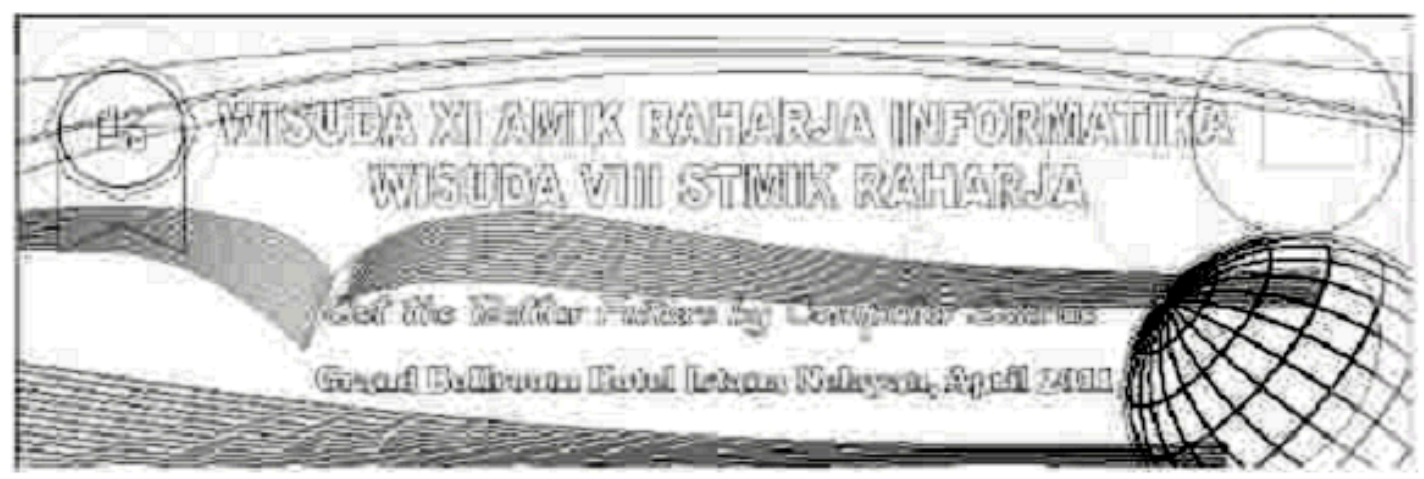

Gambar 5

Layout Kasar Desain Backdroup Wisuda 2010/2011

\section{Layout Kasar Desain Media Kartu dan Amplop Undangan}

Desain kartu dan amplop undangan dibuat dalam satu paket, corak desain kartu dan amplop dibuat senada dan harmonis dan terdapat keterkaitan antara isi kartu dan amplop undangan, di amplop berisi logo, tipografi dan alamat Perguruan Tinggi Raharja, sedangkan kartu undangan terdiri dari cover dan isi undangan, cover undangan berisi logo, tipografi, logo ISO dan alamat Perguruan Tinggi Raharja, dan isi undangan berisi kalimat undangan. Dalam rancangan ini juga didukung nilainilai grafis pendukung artistik.

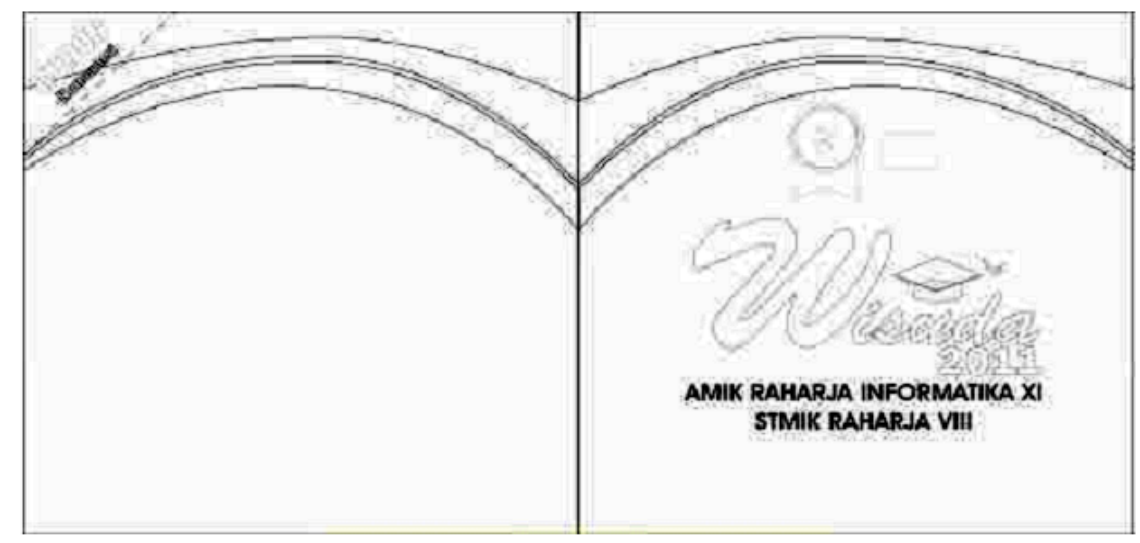

Gambar 6

Layout Kasar Desain Cover Kartu Undangan Wisuda 2010/2011

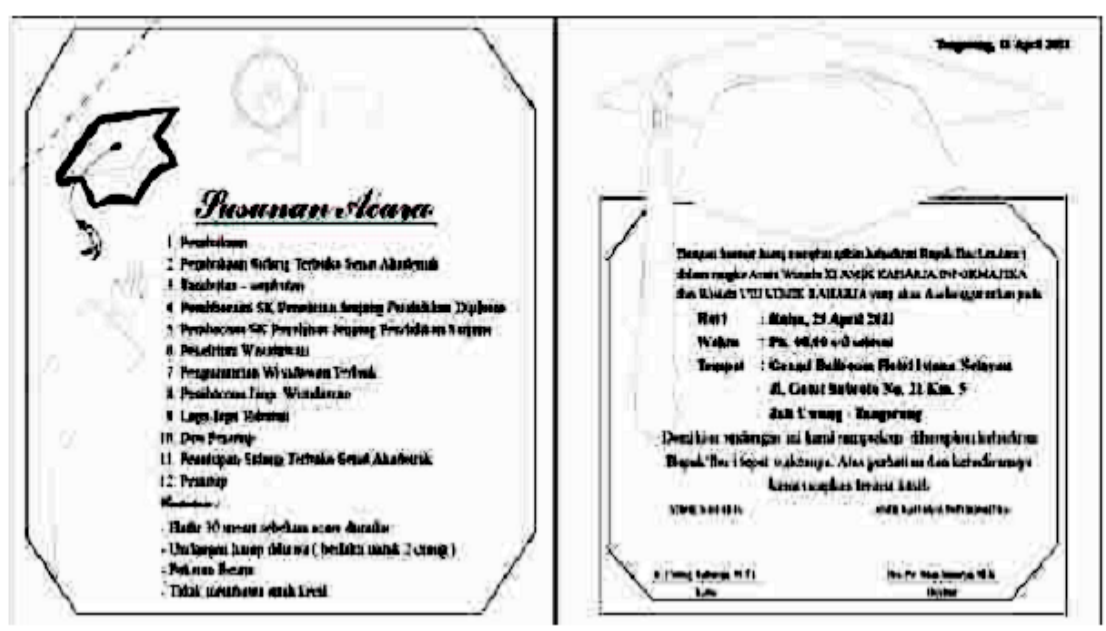

Gambar 7

Layout Kasar Desain Isi Kartu Undangan Wisuda 2010/2011 


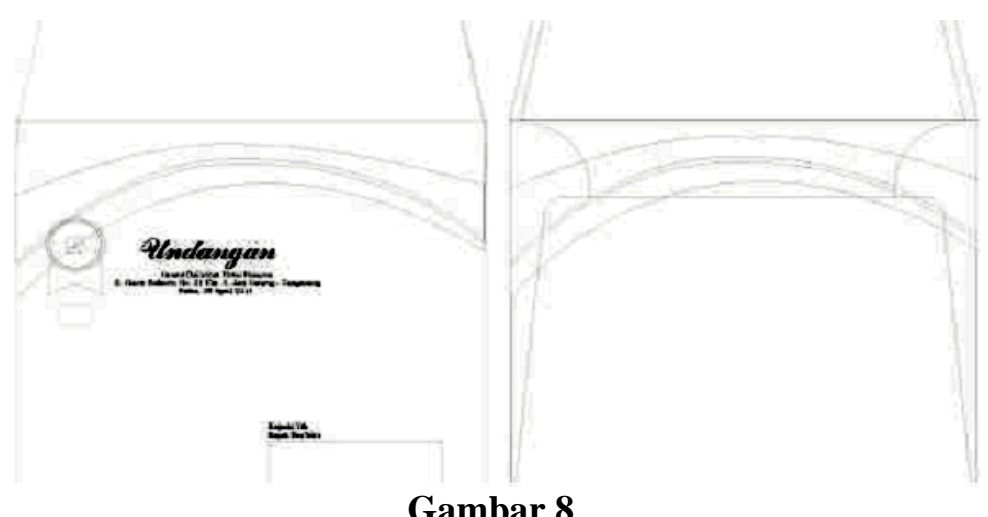

Layout Kasar Desain Amplop Undangan Wisuda 2010/2011

\section{Layout Kasar Desain Cover Buku Wisuda 2009/2010}

Desain cover buku wisuda terdiri cover depan dan cover belakang. Cover depan berisi logo atau identitas instituís, tipografi Perguruan Tinggi Raharja, logo ISO, kata-kata Wisuda XI AMIK Raharja Informatika dan Wisuda VIII STMIK Raharja, tanggal, bulan dan tahun penyelenggaraan dan kata-kata Get The Better Computer Science. Adapun cover belakang berisi alamat Perguruan Tinggi Raharja.

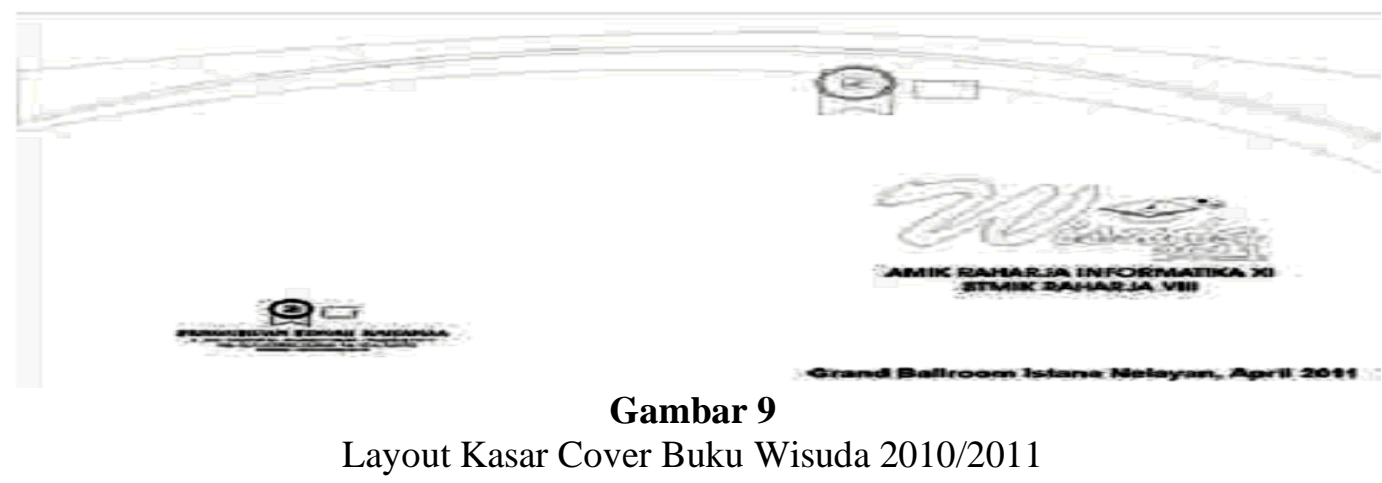

\section{Layout Kasar Desain Media Iklan Ucapan Selamat \& Sukses Kepada Wisudawan.}

Desain media iklan ucapan Selamat \& Sukses kepada para wisudawan akan dimuat di salah satu mass media, isi di dalamnya memuat logo dan tipografi Perguruan Tinggi, logo ISO, kata-kata ucapan Selamat \& Sukses kepada para wisudawan dan disertai nama, jurusan dan konsentrasi wisudawan. Layout desain akan menyesuaikan dengan besarnya ketentuan muatan mass media. Berikut layout kasar desain iklan ucapan Selamat \& Sukses kepada para wisudawan.

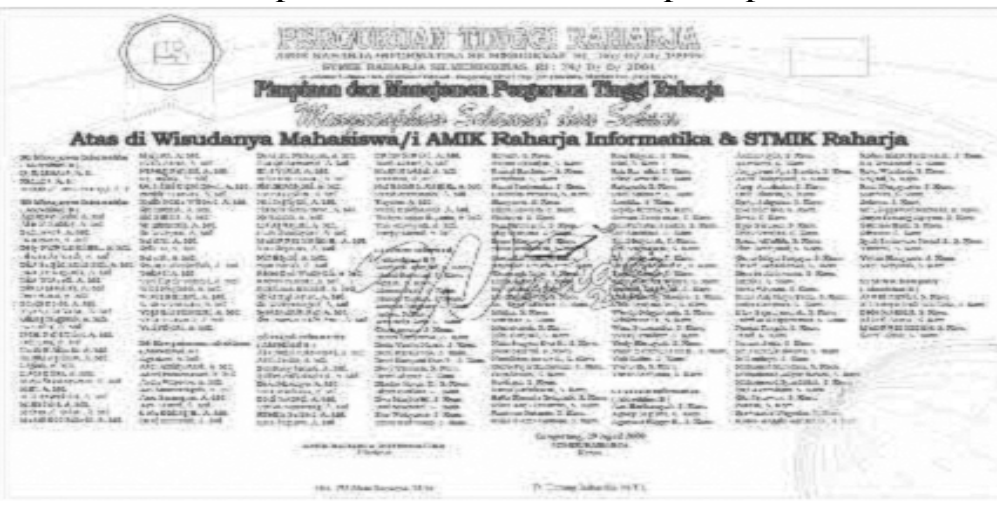

Gambar 10

Layout Kasar Desain Media Iklan Selamat \& Sukses Kepada Wisudawan 


\section{Layout Kasar Desain Kipas}

Desain Kipas menampilkan logo, tiprograp Perguruan Tinggi Raharja, Logo ISO dan Gambar boneka komputer dengan memakai toga, untuk dapat menampilkan nilai artisitik didukung oleh ornamen pendukung grafis. Berikut adalah gambar layout kasar Kipas.

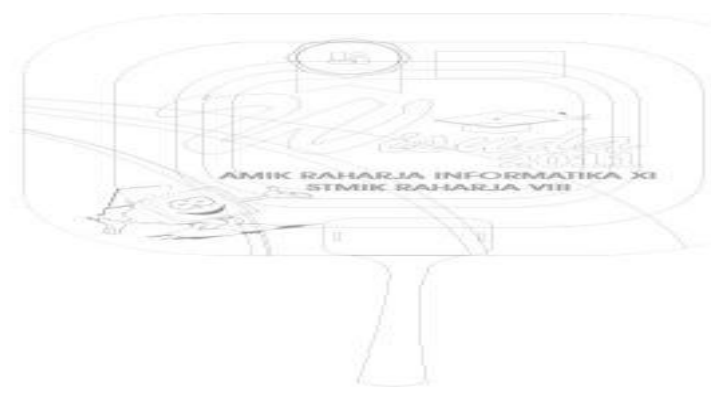

Gambar 11 Layout Kasar Desain Kipas

\section{Layout Kasar Desain Gelas}

Desain menampilkan logo, tiprograp Perguruan Tinggi Raharja, logo ISO dan tulisan wisuda 2011, untuk menampilkan nilai artisitiki didukung oleh ornamen pendukung grafis. Berikut adalah gambar layout kasar gelas.
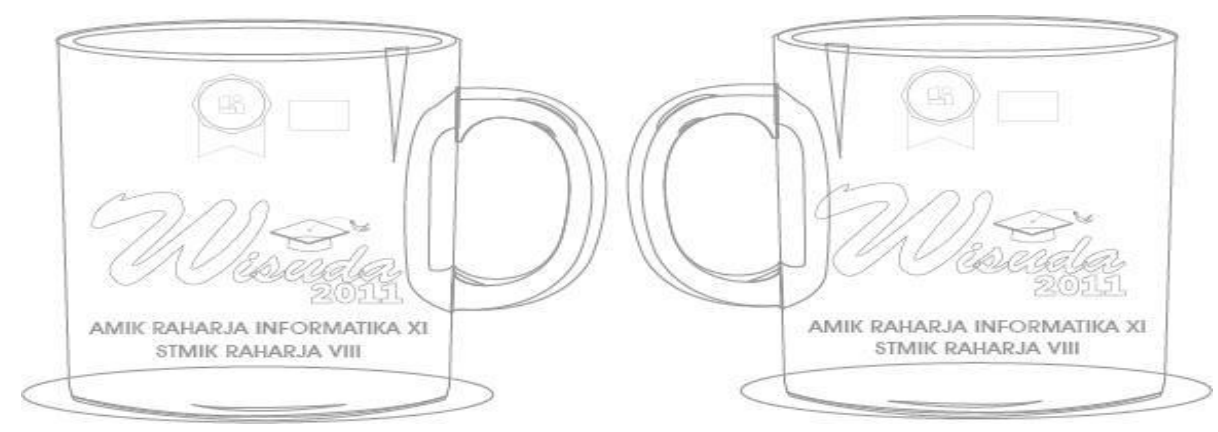

Gambar 12. Layout Kasar Desain Gelas

\section{Final Artwork}

Artwork adalah merupakan gambar kerja final yang telah melewati beberapa proses sebelumnya yaitu layout kasar. Pada proses ini naskah serta tata letak gambar merupakan proses akhir yang siap diproduksi proses cetak atau jenis produksi media secara elektronik setelah disempurnakan dengan beberapa kali revisi selama proses desain.

\section{Final Artwork Media Spanduk Luar Ruangan}

Media spanduk luar ruangan dengan isi pesan ucapan Selamat \& Sukses yang ditujukan kepada seluruh peserta wisuda dan para tamu undangan. Dibawah ini adalah desain media spanduk luar ruangan menggunakan background warna hijau yang menciptakan kesan pembaharuan dan merupakan image dari Perguruan Tinggi Raharja, juga terdapat logo atau identitas Perguruan Tinggi Raharja, logo ISO, ditambah gambar topi toga dan ditambah tulisan Wisuda 2011 yang menggunakan jenis huruf Arial Black, Banff-Normal Regular, ESCHfont Regular dan Eras Demi ITC Regular. Final artwork media spanduk luar ruangan ini ditunjukkan pada gambar 13. 


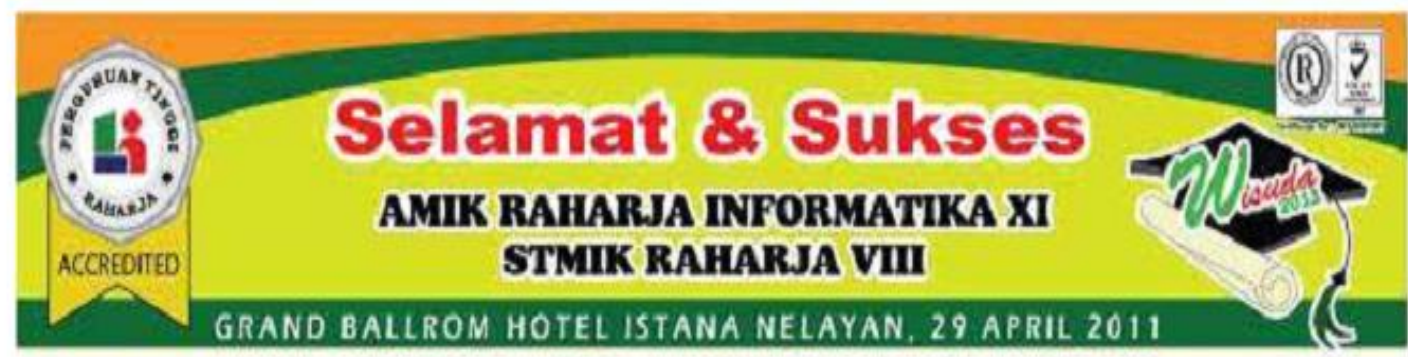

Gambar 13 Final artwork media spanduk luar ruangan

\section{Final Artwork Desain Spanduk Dalam Ruangan}

Media spanduk dalam ruangan dengan isi pesan ucapan Selamat \& Sukses yang ditujukan kepada seluruh peserta wisuda dan tentang motto tentang keunggulan-keunggulan Perguruan Tinggi Raharja Dibawah ini adalah desain media spanduk dalam ruangan menggunakan background warna hijau yang menciptakan kesan pembaharuan dan merupakan image dari Perguruan Tinggi Raharja, juga terdapat logo atau identitas Perguruan Tinggi Raharja, logo ISO, ditambah gambar topi toga dan ditambah tulisan Wisuda 2011 yang menggunakan jenis huruf Arial Black, Banff-Normal Regular, ESCHfont Regular dan Eras Demi ITC Regular. Final artwork desain spanduk dalam ruangan ini ditunjukkan pada gambar14.

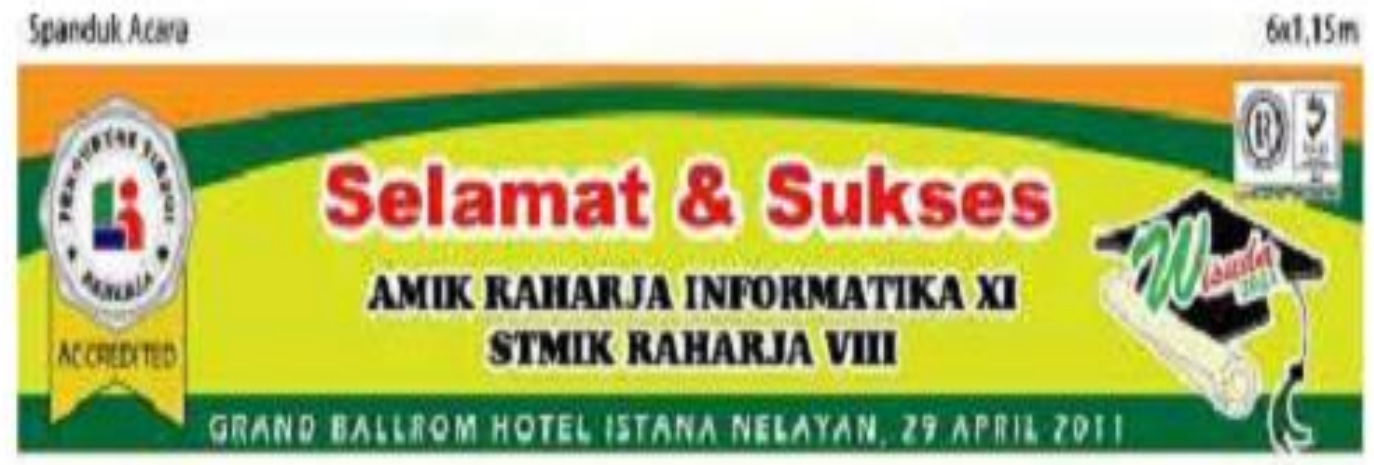

Gambar 14 Final artwork media spanduk dalam ruangan

\section{Final Artwork Media Umbul-umbul Bawah}

Media umbul-umbul digunakan untuk petunjuk tempat penyelenggaraan event sekaligus sebagai penyemarak suasana acara event, media umbul-umbul di dalamnya terdapat identitas event dengan kata Wisuda dengan menggunakan jenis huruf Banff-Normal Regular, logo atau identitas Perguruan Tinggi Raharja, logo ISO dan topi toga dengan pewarnaan dominan warna Kuning, Hijau, Oranye dan Merah dan ditambahkan bentuk-bentuk ornamen yang dipakai untuk memperkuat karakter tema penyelenggaraan event Wisuda 2011. Final Artwork media umbul-umbul bawah. Final artwork media umbul-umbul bawah ini ditunjukkan pada gambar 15 . 


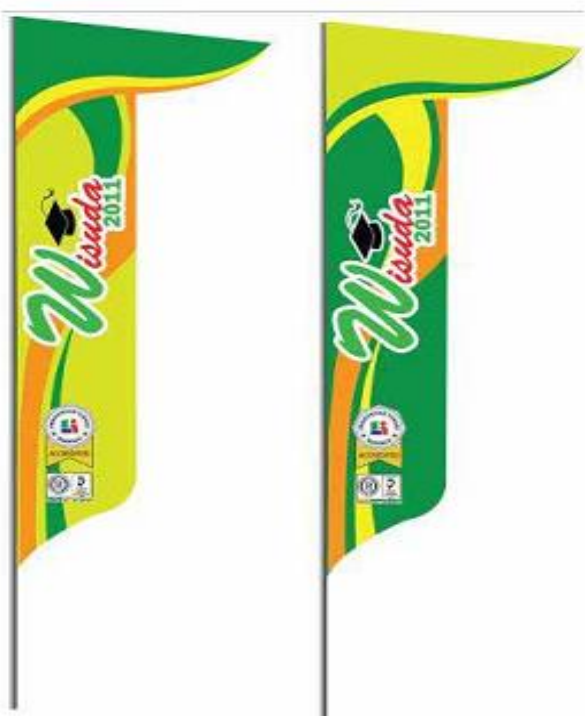

Gambar 15 Final Artwork Desain Media Umbul-umbul Bawah

\section{Final Artwork Media Umbul-umbul Atas}

Media umbul-umbul atas digunakan untuk petunjuk tempat penyelenggaraan event sekaligus sebagai penyemarak suasana acara event, media umbul-umbul di dalamnya terdapat identitas event dengan kata Wisuda dengan menggunakan jenis huruf Banff-Normal Regular, logo atau identitas Perguruan Tinggi Raharja, logo ISO, Topi Toga dan Gambar Boneka Komputer yang memakai Topi Toga dengan pewarnaan dominan warna hijau, oranye dan merah dan ditambahkan bentuk-bentuk ornamen yang dipakai untuk memperkuat karakter tema penyelenggaraan event Wisuda 2011. Final artwork media umbul-umbul atas ini ditunjukkan pada gambar 16.

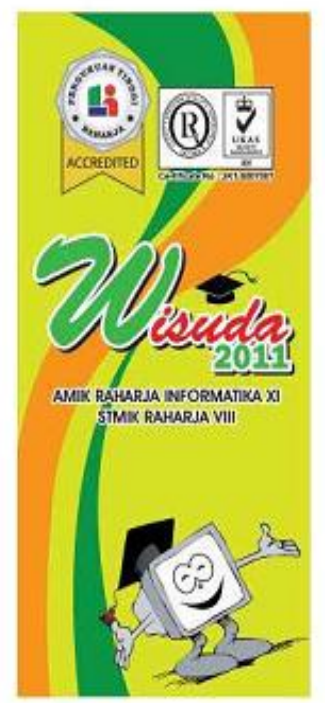

Gambar 16 Final Artwork Desain Media Umbul-umbul Atas

\section{Final Artwork Desain Backdroup}

Backdroup adalah media yang dipakai latar belakang panggung berisikan kata-kata Wisuda XI AMIK Raharja Informatika dan Wisuda VIII STMIK Raharja dengan didukung dua logo atau identitas institusi yang berada di Perguruan Tinggi Raharja adalah Logo Perguruan Tinggi Raharja dan logo ISO, selain itu terdapat kata-kata Get The Better Future By Computer Science dan tempat, tanggal, bulan tahun diselenggarakannya event wisuda. Nuansa visualisasi backdroup didukung dengan elemen-elemen garis dan gambar Bola Dunia, penggunaan jenis huruf yang dapat mendukung 
nilai-nilai artistik desain media backdroup. Final artwork desain backdroup ini ditunjukkan pada gambar 17.

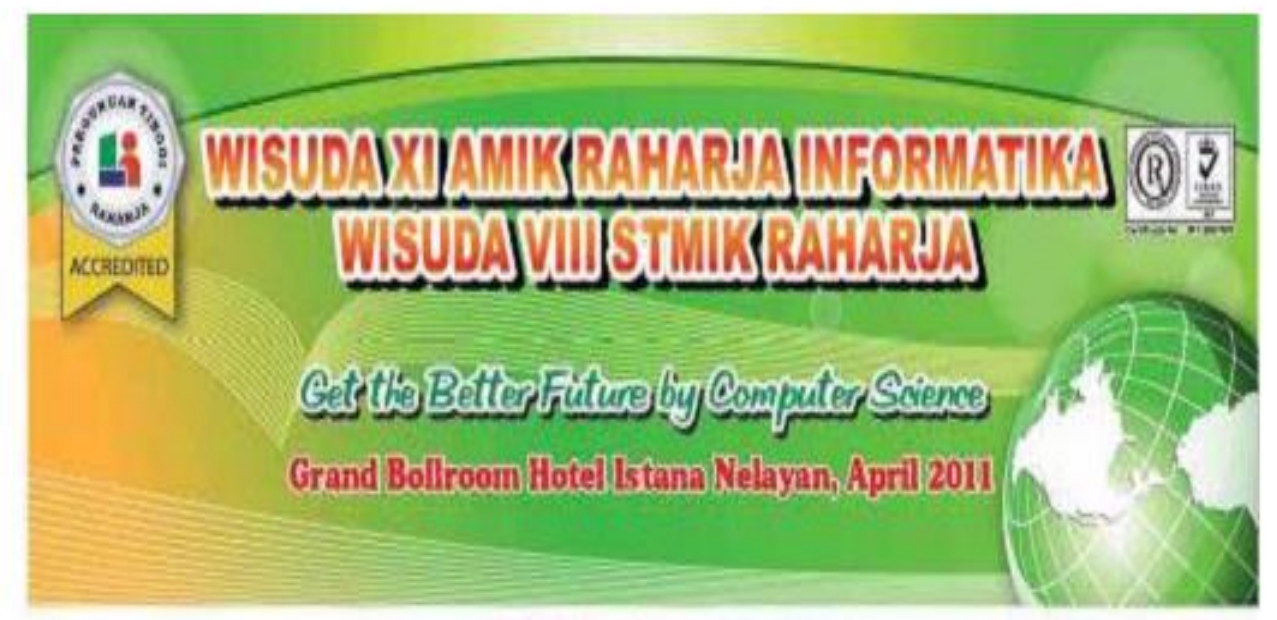

Desain Boedrasa Pangrung Wisuds 2011

Gambar 17 Final artwork desain backdroup

Final Artwork Desain Cover Buku Wisuda TA. 2010/2011

Desain cover buku wisuda 2011 terdiri dari cover depan, dan cover belakang, cover depan merupakan judul dari isi buku peserta wisuda 2011 berisi logo atau identitas dan logo ISO, cover belakang berisi logo atau identitas, logo ISO dan alamat Perguruan Tinggi Raharja. Final artwork desain cover buku wisuda TA. 2010/2011 ini ditunjukkan pada gambar 18.

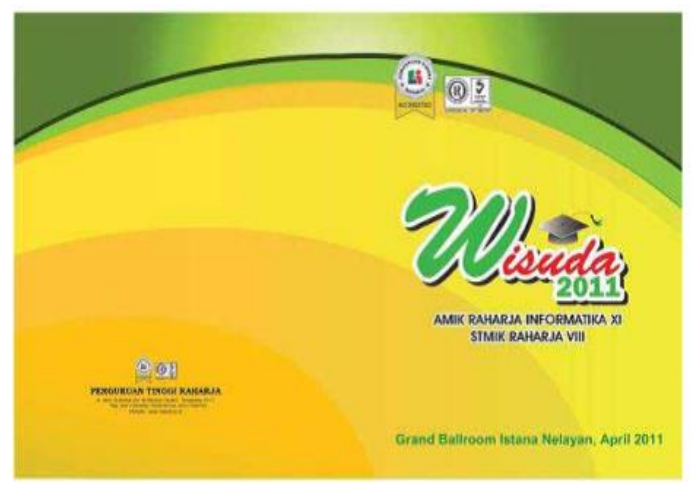

Gambar 18 Final Artwork Desain Cover Buku Wisuda 2011

\section{Final Artwork Desain Iklan Ucapan Selamat \& Sukses kepada Seluruh Peserta Wisuda 2010/2011}

Desain iklan ucapan Selamat \& Sukses kepada seluruh peserta wisuda akan dipublikasikan melalui mass media, yang berukuran sesuai dengan tempat yang telah disediakan untuk pemasangan media iklan tersebut. Final artwork desain iklan ucapan selamat \& sukses kepada seluruh peserta wisuda 2010/2011 ini ditunjukkan pada gambar 19. 


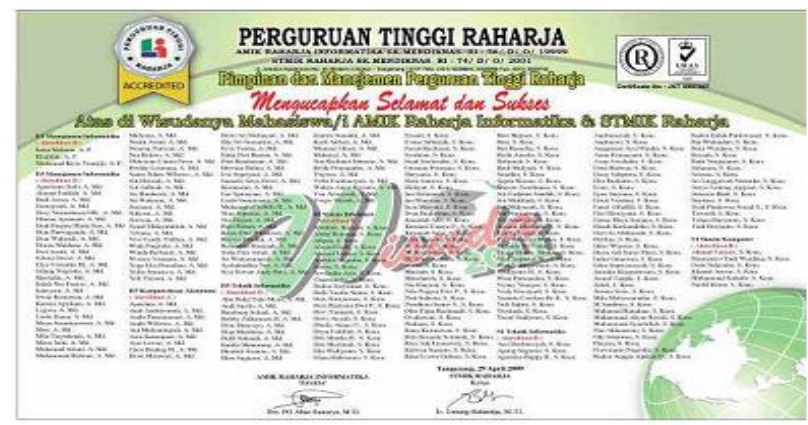

Gambar 19 Final Artwork Desain Iklan Koran

\section{Final Artwork Desain Kipas (Souvenir)}

Desain Kipas dirancang untuk kenang-kenang (Souvenir) peserta wisuda, yang berisi logo atau identitas Perguruan Tinggi Raharja logo ISO, kata wisuda 2011 dan Gambar Komputer yang memakai Topi Toga. Final artwork desain kipas (souvenir) ini ditunjukkan pada gambar 20.

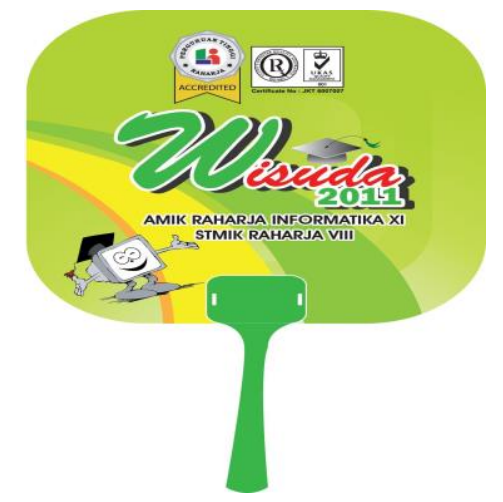

Gambar 20 Final Artwork Desain Kipas

\section{Final Artwork Desain Gelas (Souvenir)}

Desain Gelas dirancang untuk kenang-kenang (Souvenir) peserta wisuda, yang berisi logo atau identitas Perguruan Tinggi Raharja logo ISO, kata wisuda 2011. Final artwork desain gelas (souvenir) ini ditunjukkan pada gambar 21
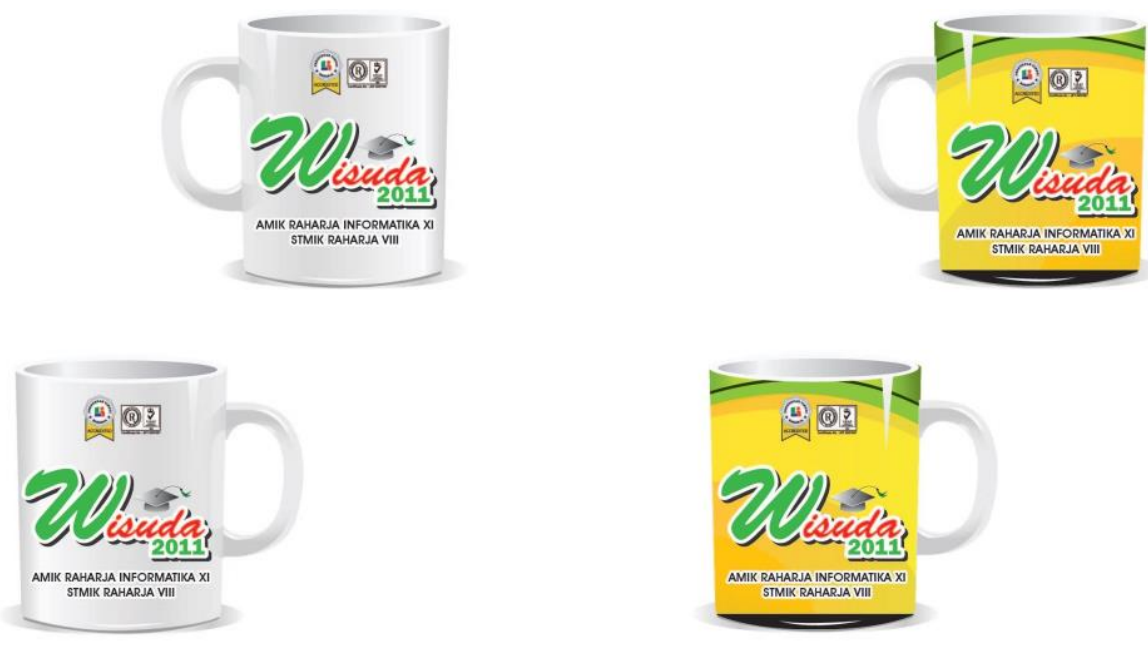

Gambar 21 Final Artwork Desain Gelas (Souvenir) 


\section{KESIMPULAN}

Media yang dibutuhkan dan efektif dalam mensukseskan penyelenggaraan event Wisuda XI AMIK Raharja Informatika dan Wisuda VIII STMIK Raharja TA. 2010/2011 terdapat 9 item yaitu Spanduk luar dan dalam, Umbul-umbul atas dan bawah, Backdroup, Kartu Undangan dan isi undangan, Cover Buku Wisuda, media iklan Ucapan Selamat \& Sukses yang ditujukan kepada peserta Wisuda yang dipasang di mass media, kipas dan gelas.

Dengan adanya rancangan media-media ini diharapkan dapat memberikan kontribusi dan nilai tambah dalam penyelenggaraan event wisuda TA. 2010/2011 dan dapat memberikan nilai nuansa yang lebih baik dan meriah sehingga dapat meningkatkan citra terhadap pihak Perguruan Tinggi Raharja. Dengan adanya rancangan media-media informasi ini dapat memperlancar penyampaian informasi penyelenggaraan event TA. 2010/2011 secara akurat, tepat dan efektif dan pada akhirnya penyelenggaraan event dapat berjalan dengan sukses dan berkualitas.

Dengan sebuah rancangan desain yang menarik dan informasi dengan tulisan yang mudah di baca dan dimengerti oleh audience, sehingga event wisuda yang dilaksanakan pesannya dapat diterima dengan baik oleh masyarakat. Konsep rancangan media-media yang diajukan penulis ini merupakan sebuah gambaran dalam upaya untuk meningkatkan image positif Perguruan Tinggi Raharja, guna menambah serta melengkapi dan penyempurnaan media sebelumnya dan dapat diteruskan oleh penulis selanjutnya.

\section{DAFTAR PUSTAKA}

[1]. Maimunah, Sunarya. Lusyani, Larasati. Nina. 2012. "Media Company Profile Sebagai Sarana Penunjang Informasi Dan Promosi”, Tangerang: Jurnal CCIT Vol.5 No.3 Mei 2012.

[2]. Immaniar, Dewi, Sudaryono dan Ningrum. Dwi Ayu. 2012. "Enriching Company Profile Sebagai Penunjang Media Informasi Dan Promosi Pada Perguruan Tinggi Raharja", Tangerang: Jurnal CCIT Vol.7 No.3 Mei 2014.

[3]. Vardiansyah, Dani. "Filsafat Ilmu Komunikasi: Suatu Pengantar". Jakarta : Penerbit Indeks, 2010.

[4]. Rahardja. Untung, Widada. Sugeng, Desrianti. Dewi Imaniar. 2010. "KPM Sebagai Pedoman Produksi Media MAVIB (Multimedia Audio Visual and Broadcasting)", Tangerang: Journal CCIT Vol.3 No.2 Januari 2010.

[5]. Tjiptono, Fandi. "Strategi Pemasaran". Jakarta : Riset Media, 2007. Supriyono, Rakhmat. "Desain Komunikasi Visual Teori”. Jakarta : Penerbit Andi, 2010.

[6]. Hendratman, Hendi. 2010. "Tips N Trik Computer Grapics Design”, Bandung: Informatika

[7]. Bandung.

[8]. Destrianti, Immaniar Dewi, Anita Wandayana dan Asih Sumaryani. 2014. "Perancangan Media Katalog Sebagai Penunjang Informasi Dan Promosi Pada Cv.Zero Store". Tangerang: Journal CCIT Vol.7 No.2. Januari 2014

[9]. Destrianti, Dewi Immaniar, Sudaryono, Dwi Ayu Ningrum. 2014. "Enriching Media Merchandise Sarana Penunjang Promosi Studi Kasus Pada Bookstore". Tangerang: Journal CCIT Vol. 7 No.3 - Mei 2014.

[10]. Maulana, Arya. Panduan Lengkap Adobe Photoshop 7.0: Jakarta, 2005. 